\title{
1071. Impact of volume resuscitation on heart rate variability in a model of hemorrhagic shock in pigs
}

\author{
E Salomão $\mathrm{Jr}^{1}$, DA Otsuki ${ }^{1 *}$, AL Corrêa ${ }^{1}$, DT Fantoni ${ }^{2}$, JOC Auler Jr ${ }^{1}$ \\ From ESICM LIVES 2014 \\ Barcelona, Spain. 27 September - 1 October 2014
}

\begin{abstract}
Introduction
Hemorrhagic shock is responsible for high mortality rates in civilian injuries and combat casualties. The initial care of these patients comprehends an early assessment of hypovolemia, bleeding management and fluid resuscitation [1], while an adequate autonomic function is essential for maintaining the hemodynamic stability during haemorrhage. The analysis of heart rate variability (HRV) has been shown as a promising noninvasive technique for assessing the cardiac autonomic modulation in trauma, and several recent studies have demonstrated an association between HRV and clinical outcome [2].
\end{abstract}

\section{Objectives}

The objective of this study was to evaluate HRV during hemorrhagic shock and fluid resuscitation, comparing to traditional hemodynamic and metabolic parameters.

\section{Methods}

Twenty pigs were submitted to acute hemorrhagic shock by removing $60 \%$ of the estimated blood volume in 15 minutes $(3 \mathrm{~mL} / \mathrm{kg} / \mathrm{min})$ and then these animals were evaluated for 60 minutes without any treatment. Surviving animals were treated with lactated Ringer solution (3:1) and evaluated for an additional period of 180 minutes. HRV metrics, as well as hemodynamic and metabolic parameters, were evaluated in survivors and non-survivors animals. Data were analysed using the repeated measures ANOVA or Friedman test (for normal and non-normal distributed date, respectively), followed by Tukey or Dunn's test as necessary. Surviving and non-surviving animals' data were compared by the unpaired t-test or Mann-Whitney U test. A multivariable logistic regression analysis was performed to estimate predictive factor for mortality resulting from hemorrhagic shock.

\section{Results}

Seven of the 20 animals have died during haemorrhage and initial fluid resuscitation. All the animals presented an increase in the $\mathrm{LF}_{\mathrm{nu}}$ and a decrease in the $\mathrm{HF}_{\mathrm{nu}}$ values after haemorrhage. However, non-surviving animals presented lower $\operatorname{LF}_{\mathrm{nu}}(72.2 \pm 18.6$ versus $85.9 \pm 7.1)$ and higher $\mathrm{HF}_{\mathrm{nu}}$ values $(27.8 \pm 18.6$ versus $14.1 \pm 7.1)$, as well as lower MAP and CI and higher levels of plasma lactate and potassium. Besides these results, the fluid resuscitation was not able to reinstate the LF and HF alterations, but restored hemodynamic and metabolic parameters.

\section{Conclusions}

The HRV metrics were able to discriminate survivors from non-survivors only at late stages of hemorrhagic shock. Moreover, metabolic variables along with $\mathrm{CI}$ and MAP were more reliable to reflect hemorrhagic shock severity than HRV metrics.

\section{Grant acknowledgment}

FAPESP.2012/00439-0

\section{Authors' details}

${ }^{1}$ Faculdade de Medicina da Universidade de São Paulo, Department of Surgery, São Paulo, Brazil. '2Faculdade de Medicina Veterinária e Zootecnia da Universidade de São Paulo, Department of Surgery, São Paulo, Brazil.

\section{Published: 26 September 2014}

${ }^{1}$ Faculdade de Medicina da Universidade de São Paulo, Department of 


\section{References}

1. Wilson M, Davis DP, Coimbra R: Diagnosis and monitoring of hemorrhagic shock during the initial resuscitation of multiple trauma patients: a review. The Journal of Emergency Medicine 2003, 24(4):413-422.

2. Winchell RJ, Hoyt DB: Spectral analysis of heart rate variability in the ICU: a measure of autonomic function. The Journal of Surgical Research 1996, 63(1):11-16.

doi:10.1186/2197-425X-2-S1-P87

Cite this article as: Salomão et al.: 1071. Impact of volume resuscitation on heart rate variability in a model of hemorrhagic shock in pigs. Intensive Care Medicine Experimental 2014 2(Suppl 1):P87.

\section{Submit your manuscript to a SpringerOpen ${ }^{\mathcal{O}}$ journal and benefit from:}

- Convenient online submission

- Rigorous peer review

- Immediate publication on acceptance

- Open access: articles freely available online

- High visibility within the field

- Retaining the copyright to your article

Submit your next manuscript at $\gg$ springeropen.com 